\title{
TESTE DE CONDUTIVIDADE ELÉTRICA NA AVALIAÇÃO DE SEMENTES DE GIRASSOL ARMAZENADAS SOB DIFERENTES TEMPERATURAS ${ }^{1}$
}

\author{
LUCIANA APARECIDA DE SOUZA ABREU², MARIA LAENE MOREIRA DE CARVALHO², \\ CRISLAINE APARECIDA GOMES PINTO ${ }^{4}$,VERÔNICA YUMI KATAOKA ${ }^{5}$
}

\begin{abstract}
RESUMO - A deterioração é um dos grandes problemas do armazenamento de sementes, principalmente das oleaginosas. Estudos recentes têm evidenciado que a eficiência do teste de condutividade elétrica pode ser influenciada pela temperatura de armazenamento das sementes. Este fato sugere que a deterioração da semente, principalmente em baixas temperaturas de armazenamento, pode não estar relacionada diretamente com a perda da integridade das membranas celulares. Para investigar o efeito de diferentes temperaturas de armazenamento sobre os resultados do teste de condutividade elétrica em sementes de girassol (Helianthus annuus L.), sementes dos híbridos Helio 250 e Helio 251 foram embaladas em papel Kraft multifoliado e armazenadas nas temperaturas: 10 e $25^{\circ} \mathrm{C}$ (constante) e $25^{\circ} \mathrm{C}$ por seis meses e depois transferidas para $10^{\circ} \mathrm{C}$ até o final do período de armazenamento, sendo que a cada três meses, num total de doze meses, a qualidade fisiológica das sementes foi avaliada pelos testes de germinação, emergência de plântulas, envelhecimento acelerado, condutividade elétrica. Também foi determinado o teor de água das sementes. O teste de condutividade elétrica não é eficiente na detecção do processo de deterioração em sementes de girassol armazenadas sob baixa temperatura.
\end{abstract}

Termos para indexação: Helianthus annuus L., semente oleaginosa, temperatura de armazenamento.

\section{ELECTRICAL CONDUCTIVITY TEST TO EVALUATE QUALITY OF SUNFLOWER SEEDS STORED AT DIFFERENT TEMPERATURES}

\begin{abstract}
Deterioration is a problem in seed storage, particularly for oleaginous seeds. Research has shown that conductivity test results may be influenced by seed storage temperatures suggesting that seed deterioration, especially at low temperatures, does not seem to be directly related to the loss of cell membrane integrity. To investigate the effect of different storage temperatures on electrical conductivity in sunflower seeds (Helianthus annuus L.), seeds of two sunflower hybrids, Helio 250 and Helio 251, were packaged in layered Kraft paper and stored at the following temperatures: $10^{\circ} \mathrm{C}, 25^{\circ} \mathrm{C}$ and $25 / 10^{\circ} \mathrm{C}$. Seed physiological quality was evaluated every three months during a 12 months storage period from germination, seedling emergence, accelerated aging and electrical conductivity tests. Seed water content was also determined. The electrical conductivity test was not efficient in detecting deterioration in sunflower seed stored at low temperatures.
\end{abstract}

Index terms: Helianthus annuus L., oleaginous seed, storage temperatures.

\footnotetext{
${ }^{1}$ Submetido em 14/06/2010. Aceito para publicação em 01/04/2011, parte da Tese de Doutorado em Fitotecnia pelo primeiro autor.

${ }^{2}$ Eng. Agr., DSc., UFLA, Cx. Postal 3037, 37.200-000, Lavras, MG; E-mail:luapsouza2003@yahoo.com.br.
}

${ }^{3}$ Eng. Agr., DSc., Prof. Titular do Departamento de Agricultura da UFLA; E-mail: mlaenemc@ufla.br

${ }^{4}$ Graduanda em Agronomia, UFLA; E-mail: crislainepinto@yahoo.com.br

${ }^{5}$ Eng. Agr., DSc., Prof. UNIBAN; E-mail: veronicayumi@terra.com.br 


\section{INTRODUÇÃO}

As pesquisas com o girassol (Helianthus annuus L.) relativas à avaliação da qualidade fisiológica das sementes são essenciais para o programa de controle de qualidade e ao estabelecimento da cultura e justificam-se pela potencialidade da espécie e pela escassez de informações referentes à tecnologia de conservação de sementes oleaginosas.

O procedimento atualmente utilizado para a determinação da qualidade de sementes de girassol é o teste de germinação (Brasil, 2009), que apresenta limitações por não detectar variações entre os lotes em estádio inicial de deterioração e nem sempre revela diferenças de desempenho entre lotes durante o armazenamento ou em campo (Carvalho e Nakagawa, 2000). Essas diferenças podem ser elucidadas pelo fato de que as primeiras alterações nos processos bioquímicos associados à deterioração ocorrem, geralmente, antes que sejam verificados declínios na capacidade germinativa (Delouche e Baskin, 1973). Por essa razão, vários métodos têm sido indicados para avaliar o vigor das sementes como complemento as informações obtidas no teste de germinação.

De acordo com Delouche e Baskin, (1973) a degradação do sistema de membranas celulares é a primeira etapa do processo de deterioração de sementes. Desse modo, os testes mais indicados para investigar diferenças sutis de vigor entre diferentes lotes são aqueles que avaliam a estrutura dessas membranas (Basra, 1995; Desai et al., 1997), detectando a deterioração das sementes em sua fase inicial (Vieira, 1994). Dentre os procedimentos utilizados com tal finalidade, o teste de condutividade elétrica tem se destacado na avaliação do vigor em sementes de várias espécies devido sua facilidade de execução, baixo custo, rapidez, reprodutividade e fácil interpretação de resultados (Vieira e Krzyzanowski, 1999).

$\mathrm{O}$ teste de condutividade elétrica é um método rápido e eficiente de determinação do vigor que visa avaliar indiretamenteaintensidadedosdanoscausadosàsmembranas celulares resultantes do processo de deterioração da semente. A técnica consiste na quantificação dos eletrólitos liberados pela semente na água de embebição sendo essa quantidade proporcional ao grau de desorganização da membrana plasmática, seguida de redução na perda de solutos, à medida que os tecidos são reidratados, até alcançarem um estado de equilíbrio (Simon e Raja Harun, 1972). Baixos valores de condutividade elétrica correspondem à menor liberação de exsudatos e indicam alto potencial fisiológico, ou seja, menor intensidade de desorganização do sistema de membranas das células (Vieira et al., 2002).

Existem poucos relatos de pesquisas com ênfase à aplicação do teste de condutividade elétrica para estimar o efeito do armazenamento na qualidade fisiológica da semente. Em alguns estudos verificou-se que os resultados dessa técnica podem ser influenciados pela temperatura de armazenamento, sugerindo que a deterioração das sementes em temperaturas mais baixas parece não se relacionar diretamente com a perda da integridade das membranas celulares (Panobianco e Vieira, 2007), devido ao seu reparo ou reorganização durante o armazenamento a baixas temperaturas.

Segundo Ferguson (1988), sementes de soja armazenadas a $10{ }^{\circ} \mathrm{C}$ tiveram sua qualidade fisiológica reduzida quando avaliadas pelos testes de germinação e envelhecimento acelerado, no entanto, o teste de condutividade elétrica não detectou este fato. $\mathrm{O}$ teste de condutividade elétrica também não foi apropriado para avaliação do vigor em sementes de soja (Vieira et al., 2001; Fessel, 2001) e ervilha (Panobianco et al., 2007) sob o armazenamento a $10^{\circ} \mathrm{C}$, pois conforme relato dos autores a deterioração da semente a essa temperatura pode não estar relacionada à perda da integridade das membranas, ou pode haver um processo de reorganização das membranas que reduz a quantidade de lixiviados na solução de embebição das sementes.

Dessa maneira, a pesquisa foi realizada com o objetivo de investigar o efeito de diferentes temperaturas de armazenamento $\left(10 ; 25\right.$ e $\left.25 / 10{ }^{\circ} \mathrm{C}\right)$ no vigor de sementes de girassol avaliado pelo teste de condutividade elétrica.

\section{MATERIAL E MÉTODOS}

A pesquisa foi realizada no Laboratório Central de Sementes da Universidade Federal de Lavras (UFLA) MG, no período de maio de 2008 a maio de 2009. Foram utilizadas sementes de dois híbridos de girassol Helio 250 e Helio 251, embaladas em sacos de papel Kraft multifoliado e armazenadas nas seguintes temperaturas: 10 e $25{ }^{\circ} \mathrm{C}$ (constante) e $25{ }^{\circ} \mathrm{C}$ por seis meses e depois transferidas para $10^{\circ} \mathrm{C}$ até o final do período de armazenamento. A cada três meses, num total de 12 meses de armazenamento, a qualidade fisiológica das sementes de girassol foi avaliada pelos seguintes testes: germinação - realizada a $25{ }^{\circ} \mathrm{C}$ com quatro repetições de 50 sementes por tratamento. As contagens foram efetuadas aos quatro e 10 dias após a semeadura (Brasil, 2009); emergência de plântulas 
- realizada com quatro repetições de 50 sementes por tratamento, semeadas em bandejas plásticas com dimensões de $60 \times 40 \times 10 \mathrm{~cm}$ contendo substrato terra e areia na proporção $2: 1$, e com saturação do substrato regulado para $60 \%$. As bandejas foram acondicionadas em câmara de crescimento a $25^{\circ} \mathrm{C}$, sendo a emergência das plântulas computada aos 10 dias após a semeadura, avaliandose o número de plântulas emergidas; envelhecimento acelerado - foi conduzido de acordo com a metodologia recomendada pela AOSA (1983). Quatro repetições de 50 sementes por tratamento que foram dispostas sobre tela de alumínio em caixa de plástico $(11 \times 11 \times 3,5 \mathrm{~cm})$. Em cada caixa foram colocados $40 \mathrm{~mL}$ de água, e em seguida, mantidos a $42{ }^{\circ} \mathrm{C}$ por 48 horas (Adamo et al., 1984). Após esse período, as sementes foram submetidas ao teste de germinação conforme Brasil (2009). Antes da realização dos procedimentos para se avaliar a qualidade fisiológica das sementes determinou-se o teor de água das mesmas pelo método de estufa a $105{ }^{\circ} \mathrm{C}$ por 24 horas (Brasil, 2009).

O teste de condutividade elétrica foi conduzido com quatro repetições de 50 sementes, que foram pesadas e colocadas para embeber em copos de plástico $(200 \mathrm{~mL})$ contendo $75 \mathrm{~mL}$ de água desionizada $\left(<2,0 \mu \mathrm{S} . \mathrm{cm}^{-1}\right)$. Em seguida foram mantidas em câmara de germinação, à temperatura constante de $25^{\circ} \mathrm{C}$, por 24 horas (Brandão JR. et al., 1997). Após o período de condicionamento, a condutividade elétrica da solução foi medida por meio de leitura em condutivímetro, marca Digimed, modelo CD21, sendo os resultados expressos em $\mu \mathrm{S} . \mathrm{cm}^{-1} \cdot \mathrm{g}^{-1}$.

Delineamento experimental - foi utilizado o delineamento inteiramente casualizado com quatro repetições em esquema fatorial $3 \times 5$, correspondente a três temperaturas de armazenamento $\left(10,25\right.$ e $\left.25 / 10^{\circ} \mathrm{C}\right)$ e cinco épocas de avaliação (zero, três, seis, nove e 12 meses). Para os resultados dos testes de germinação, envelhecimento acelerado, emergência de plântulas e condutividade elétrica foram realizadas análises de regressão para cada híbrido separadamente.

\section{RESULTADOS E DISCUSSÃO}

Nota-se pelos resultados dos testes de germinação e vigor, que a deterioração das sementes do híbrido Helio 251 em relação às sementes do híbrido Helio 250 , foi mais acentuada em todos os tratamentos testados devido a sua qualidade inicial (Tabela 1). Dentre os fatores que afetam a qualidade das sementes durante o armazenamento a qualidade inicial do lote é relevante, pois a manutenção da qualidade fisiológica das sementes no decorrer do tempo vai depender diretamente dela, dentre outros fatores.

\begin{tabular}{|c|c|c|c|c|c|}
\hline \multirow{2}{*}{ Híbrido } & \multirow{2}{*}{$\begin{array}{l}\text { Teor de } \\
\text { água }\end{array}$} & \multicolumn{4}{|c|}{ Testes de germinação e vigor } \\
\hline & & $\mathrm{G}$ & $\mathrm{E}$ & EA & $\mathrm{CE}$ \\
\hline Helio 250 & 7,8 & 94 & 97 & 88 & 58,53 \\
\hline Helio 251 & 8,5 & 84 & 78 & 62 & 68,00 \\
\hline
\end{tabular}

Pelos resultados de germinação das sementes dos híbridos de girassol, Helio 250 e Helio 251 (Figura 1) observa-se, de maneira geral, decréscimo na germinação com o decorrer do período de armazenamento em todas as temperaturas testadas, ressaltando que ambos os genótipos seguiram a tendência de queda na qualidade fisiológica após três meses de armazenamento. $\mathrm{O}$ armazenamento a baixa temperatura propiciou a manutenção de melhor qualidade fisiológica das sementes de girassol em relação àquelas armazenadas a $25{ }^{\circ} \mathrm{C}$, porém a redução na germinação ocorreu independente da temperatura de armazenamento.

Os dados referentes ao vigor das sementes de girassol avaliado pelo teste de emergência de plântulas estão na Figura 2. Para o híbrido Helio 250, não foram detectadas diferenças significativas entre os tratamentos testados durante os seis primeiros meses de armazenamento, inclusive com destaque para a elevada porcentagem de emergência. As sementes do híbrido Helio 251 tiveram resultados semelhantes aos obtidos no teste de germinação, enfatizando a tendência de redução na qualidade fisiológica das mesmas pela diminuição da porcentagem de plântulas emergidas após seis meses de armazenamento nas diferentes temperaturas testadas. $\mathrm{Na}$ temperatura de $10{ }^{\circ} \mathrm{C}$, o vigor das sementes tendeu a ser mantido durante todo o período de armazenamento, sem alterações significativas. Mais uma vez, esses resultados evidenciam que o armazenamento em baixas temperaturas proporciona melhor conservação das sementes de girassol, minimizando o processo de deterioração. Deve-se ressaltar que a emergência de plântulas foi realizada em condições controladas, tais como temperatura e disponibilidade de água, o que favoreceu o desempenho das sementes mais vigorosas, com destaque para as do híbrido Helio 250 . 


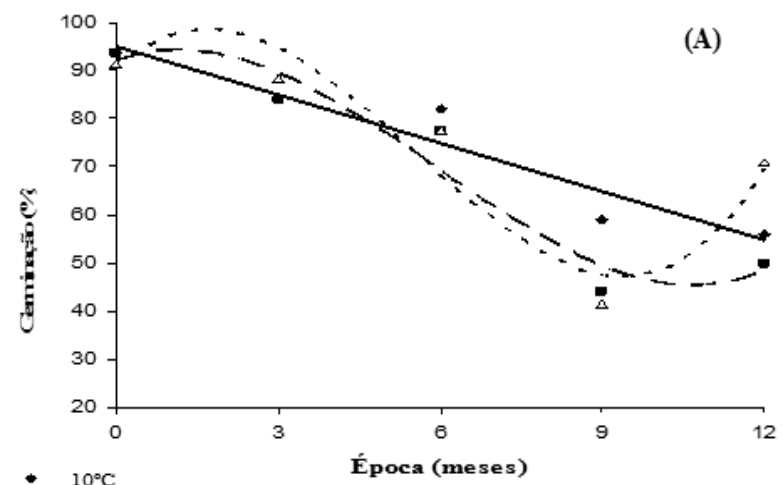

- $25^{\circ} \mathrm{C}$

$\triangle 25 / 10^{\circ} \mathrm{C}$

$y=-3,350 x+95,100 R^{2}=91,95 \%$

$y=0,113 x^{3}-1,998 x^{2}+4,105 x+92,121 R^{2}=92,92 \%$

$y=0,227 x^{3}-3,786 x^{2}+10,815 x+89,964 R^{2}=89,64 \%$

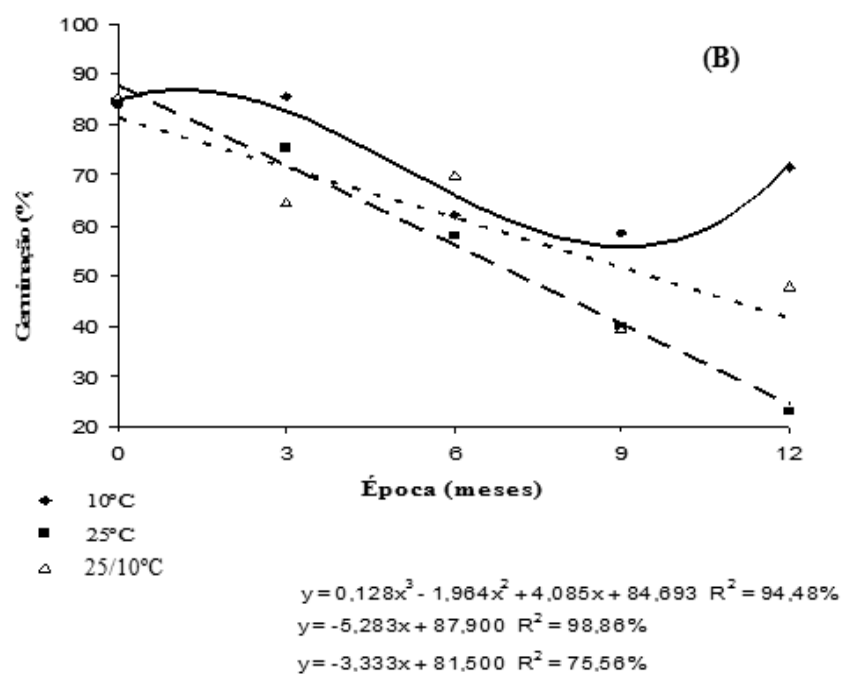

FIGURA 1. Germinação (\%) das sementes dos híbridos Helio 250 (A) e Helio 251 (B) em função das épocas analisadas para as temperaturas estudadas.

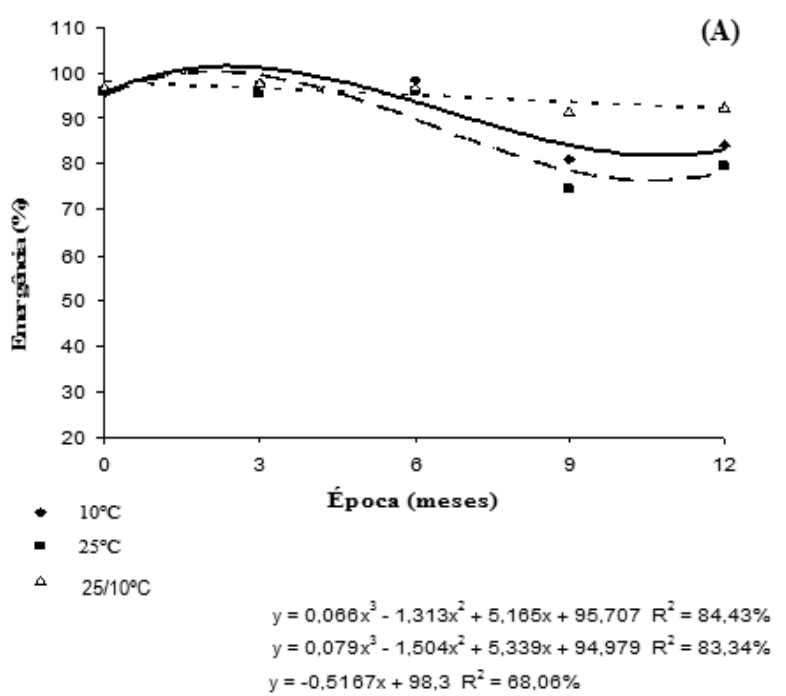

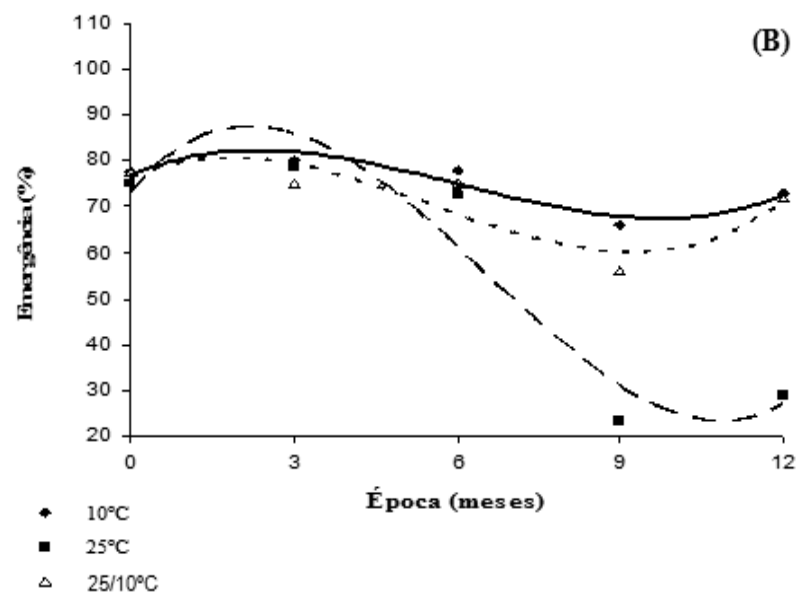

$y=0.073 x^{3}-1.313 x^{2}+4.942 x+77.007 R^{2}=86.42 \%$ $y=0.197 x^{3}-3,865 x^{2}+14,103 x+73,129 R^{2}=91,62 \%$ $y=0.100 x^{3}-1.683 x^{2}+5.049 x+76.421 R^{2}=72.87 \%$

FIGURA 2. Emergência de plântulas (\%) dos híbridos Helio 250 (A) e Helio 251 (B) em função das épocas analisadas para as temperaturas estudadas.

Os resultados da análise do teste de envelhecimento acelerado encontram-se na Figura 3. Para as sementes do híbrido Helio 250, nas diferentes épocas estudadas, não foram detectadas variações em função das temperaturas de armazenamento. As sementes desse híbrido apresentaram tendência linear decrescente em relação aos valores de germinação após o envelhecimento acelerado durante os 12 meses de armazenamento. De modo geral, verificouse para as sementes do híbrido Helio 251 tendência de redução significativa na germinação das sementes envelhecidas artificialmente durante o armazenamento. Houve uma redução de 3,04 \% (coeficiente angular) na 
porcentagem de plântulas normais após o envelhecimento acelerado das sementes a cada unidade de variação nos períodos de armazenamento, ou seja, a cada mês de armazenamento.
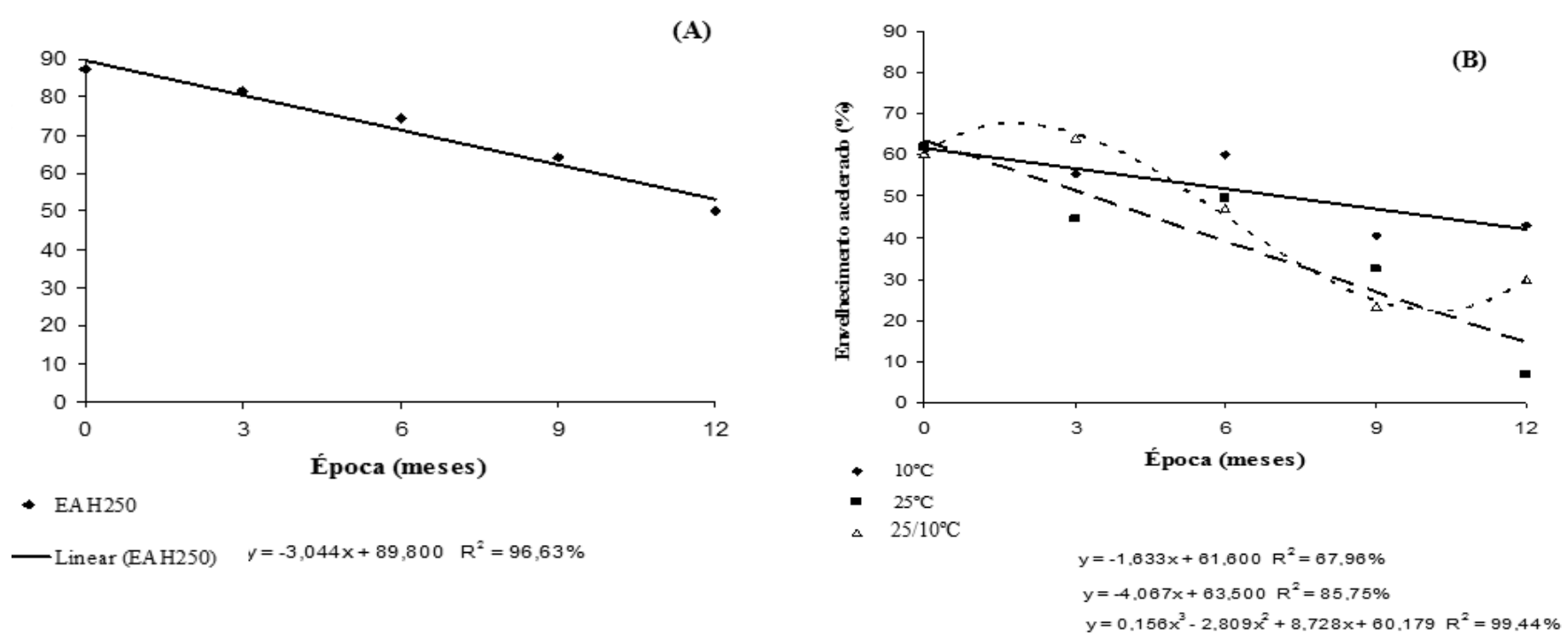

\section{FIGURA 3. Germinação (\%) após envelhecimento acelerado para os híbridos Helio 250 (A) e Helio 251 (B) em função das épocas analisadas para as temperaturas estudadas.}

Após 12 meses de armazenamento a redução estimada no vigor das sementes foi $36,48 \%$. A condição de estresse imposta pelo teste de envelhecimento reduziu consideravelmente o número de plântulas normais após nove meses de armazenamento. Vale ressaltar ainda, no caso do tratamento $25 / 10{ }^{\circ} \mathrm{C}$, que a transferência das sementes do ambiente não controlado para a câmara fria $\left(10^{\circ} \mathrm{C}\right)$ após seis meses não resultou em redução no processo deteriorativo das sementes corroborando com os resultados do teste de envelhecimento acelerado obtidos por Panobianco e Vieira (2007) para sementes de soja e Panobianco et al., (2007) para sementes de ervilha.

A lixiviação de eletrólitos das sementes de girassol, mensurada pela condutividade elétrica da água de embebição está apresentada na Figura 4. Com relação aos dados de condutividade elétrica das sementes do híbrido Helio 250, não foram observadas diferenças significativas entre as sementes armazenadas a $10{ }^{\circ} \mathrm{C}$ e as sementes armazenadas a 25 e $25 / 10{ }^{\circ} \mathrm{C}$ durante as épocas avaliadas, resultado semelhante ao verificado no teste de envelhecimento acelerado para sementes desse genótipo.
No entanto, esse fato evidencia diferenças em relação aos resultados obtidos pelos testes de germinação e emergência de plântulas, que apontam diferenças entre os tratamentos e queda na qualidade fisiológica das sementes armazenadas a baixa temperatura após seis meses.

Os dados relatados põem em questionamento a confiabilidade dos resultados obtidos pelo teste de condutividade elétrica para avaliação da qualidade de sementes armazenadas a baixas temperaturas. Conforme verificado por Pontes et al., (2006), os valores de condutividade elétrica foram constantes em sementes de sibipiruna (Caesalpinia peltophoroides Benth.) armazenadas a $5{ }^{\circ} \mathrm{C}$, porém, naquelas que permaneceram em ambiente a $20{ }^{\circ} \mathrm{C}$, houve aumento significativo da condutividade durante o período de armazenamento.

$\mathrm{O}$ teste de condutividade elétrica na avaliação do vigor das sementes do híbrido Helio 250 foi sensível em detectar a taxa de deterioração das sementes ao longo do armazenamento, porém não possibilitou caracterizar de maneira eficiente os tratamentos testados, pois ocorreram variações entre os resultados obtidos por este teste e os 
demais. Na literatura existem resultados semelhantes obtidos para sementes de outra oleaginosa, a soja (Ferguson, 1988; Vieira et al., 2001; Panobianco e Vieira, 2007) indicando que a quantidade de íons lixiviados pelas sementes é influenciada pela temperatura de armazenamento. Conforme relato de Fessel et al. (2010), o armazenamento de sementes de soja a $10{ }^{\circ} \mathrm{C}$ tendeu a estabilizar a integridade das membranas, refletindo em menor lixiviação de exsudados. As sementes de girassol possuem estruturas morfológicas distintas das sementes

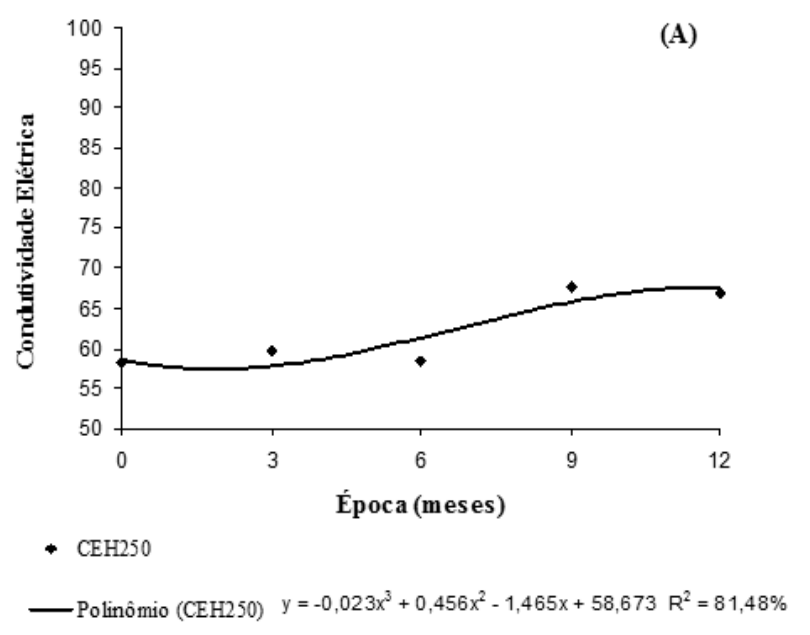

de soja e, em alguns casos, as causas do insucesso do teste de condutividade têm sido associadas a características do tegumento, o que ocasiona em liberação mais ou menos acentuada dos lixiviados (Panobianco e Marcos Filho, 2001). Brandão JR et al. (1997), utilizaram o teste de condutividade na avaliação de sementes íntegras e destegumentadas de girassol e verificaram que sementes destegumentadas, embebidas por 18 e 24 horas, foram mais eficientes em detectar diferenças de qualidade existentes entre lotes.

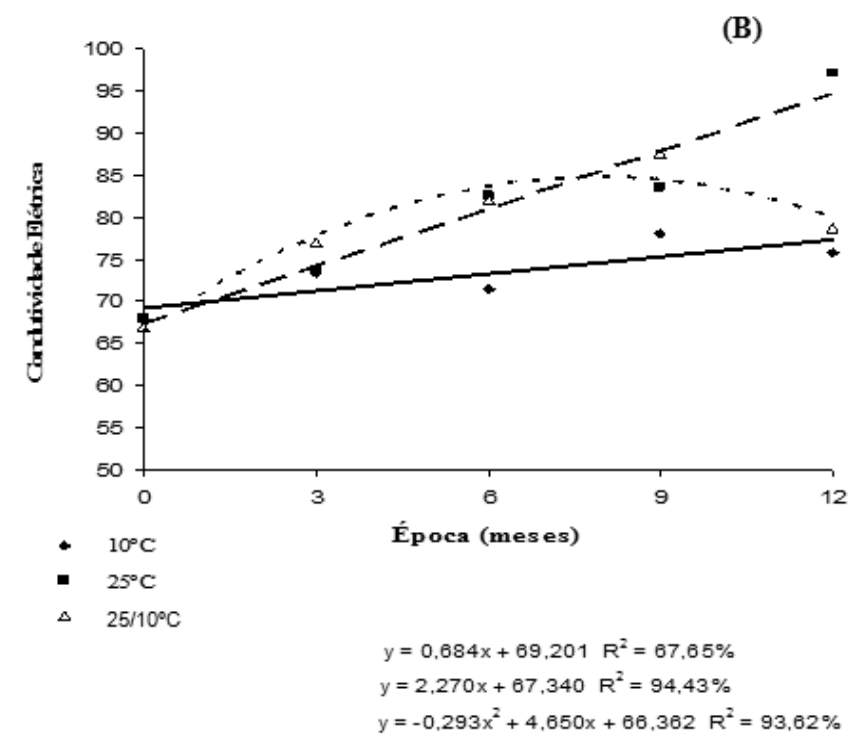

FIGURA 4. Condutividade elétrica $\left(\mu \mathrm{S} . \mathrm{cm}^{-1} \cdot \mathrm{g}^{-1}\right)$ para os híbridos Helio 250 (A) e Helio 251 (B) em função das épocas analisadas para as temperaturas estudadas.

O processo de embebição de água pela semente permite a reestruturação do sistema de membranas celulares reduzindo a permeabilidade e, consequentemente, a liberação de lixiviados (Bewley e Black, 1994), porém pelos resultados obtidos para sementes de girassol do híbrido Helio 250, sugere-se que as membranas são reorganizadas também quando essas sementes são armazenadas a baixas temperaturas, pois se constatou que após serem transferidas para $10{ }^{\circ} \mathrm{C}$, no sexto mês de armazenamento, não houve alteração nos valores de condutividade elétrica.

Para as sementes do híbrido Helio 251, a partir do sexto mês, o armazenamento a $10{ }^{\circ} \mathrm{C}$ destacou-se devido aos baixos valores de condutividade, ou seja, nas avaliações subsequentes esse tratamento foi considerado o que melhor manteve a qualidade das sementes como já era esperado. Foram verificados valores crescentes de condutividade elétrica das sementes de girassol durante o armazenamento em todas as temperaturas estudadas até os nove meses, no entanto houve redução desses valores na última avaliação, ou seja, após 12 meses de armazenamento para as sementes armazenadas inicialmente a $25^{\circ} \mathrm{C}$ e que aos seis meses foram transferidas para $10{ }^{\circ} \mathrm{C}$.

Durante as épocas de armazenamento, à temperatura de $25{ }^{\circ} \mathrm{C}$, as sementes apresentaram maior intensidade de lixiviação de eletrólitos em comparação às demais temperaturas estudadas, o que pode ser atribuído ao avanço do processo deteriorativo causado por elevadas 
temperaturas de armazenamento. Segundo Panobianco e Vieira (2007), quando se trabalha com altas temperaturas (20 e $25^{\circ} \mathrm{C}$ ), alterações significativas são verificadas nos valores de condutividade elétrica durante as épocas de armazenamento, revelando aumento na perda de lixiviados com o decorrer do tempo.

É interessante acrescentar ainda que para o híbrido Helio 251, os resultados de condutividade elétrica das sementes são coerentes com os obtidos nos testes de germinação e vigor. Observou-se também que os valores condutividade obtidos pelas sementes armazenadas à temperatura de $10{ }^{\circ} \mathrm{C}$ variou pouco durante os 12 meses de armazenamento, corroborando com o fato de que o teste de condutividade elétrica em sementes armazenadas a baixas temperaturas, especialmente $10^{\circ} \mathrm{C}$, não se constitui num procedimento eficiente para avaliação da qualidade fisiológica de sementes armazenadas. Isso pode ser comprovado também analisando o tratamento $25 / 10{ }^{\circ} \mathrm{C}$, pois, após a alteração da temperatura de armazenamento, houve redução dos valores de condutividade elétrica que seguiam tendência crescente até então, sugerindo que as membranas se estabilizaram nas sementes de girassol armazenadas a $10{ }^{\circ} \mathrm{C}$.

Desta forma, pelo teste de condutividade elétrica não foi possível detectar diferenças na deterioração de sementes armazenadas nas diferentes temperaturas para o híbrido Helio 250. No entanto, foi possível detectar a evolução da deterioração ao longo do armazenamento para as sementes dos dois híbridos.

\section{CONCLUSÃO}

O teste de condutividade elétrica não é eficiente na detecção do processo de deterioração em sementes de girassol armazenadas sob baixa temperatura.

\section{AGRADECIMENTOS}

À Fundação de Amparo a Pesquisa do Estado de Minas Gerais (Fapemig), pela concessão da bolsa de estudos, ao CNPq e a CAPES pelo apoio financeiro para realização da pesquisa.

\section{REFERÊNCIAS}

ADAMO, P.E.; SADER, R.; BANZATTO, D.A. Influência do tamanho na produção e qualidade de sementes de girassol. Revista Brasileira de Sementes, v.6, n.3, p.9-14,
1984.

AOSA - ASSOCIATION OF OFFICIAL SEED ANALYSTS. Seed vigor testing handbook. East Lansing: AOSA, 1983. 88p. (Contribution, 32).

BASRA, A.S. Seed quality: basic mechanisms and agricultural implications. New York, 1995. 389p.

BEWLEY, J.D.; BLACK, M. Seeds: physiology of development and germination. New York: Plenum Press, 1994. 444p.

BRANDÃO JR., D.S.; RIBEIRO, D.C.A.; BERNARDINO FILHO, J.R.; VIEIRA, M.G.G.C. Adequação do teste de condutividade elétrica para determinar a qualidade fisiológica de sementes. Informativo ABRATES, v.7, n. 1/2, p.184, 1997.

BRASIL. Ministério da Agricultura, Pecuária e Abastecimento. Regras para análises de sementes. Ministério da Agricultura, Pecuária e Abastecimento. Secretaria de Defesa Agropecuária. Brasília, DF: Mapa/ ACS, 2009. 395p.

CARVALHO, N.M.; NAKAGAWA, J. Sementes: ciência, tecnologia e produção. 4.ed. Jaboticabal: FUNEP, 2000. $588 \mathrm{p}$.

DELOUCHE, J.C.; BASKIN, C.C. Accelerated aging techniques for predicting the relative storability seed lots. Seed Science and Technology, v.1, n.2, p.427-252, 1973.

DESAI, B.B.; KOTECHA, P.M.; SALUNKHE, D.K. Seeds handbook. New York, 1997. 627p.

FERGUSON, J.M. Metabolic and biochemical changes during the early stages of soybean seed deterioration. 1988. 138p. Thesis (Ph.D.) - University of Kentucky, Lexington.

FESSEL, S.A. Condutividade elétrica em sementes de soja em função da temperatura e do período de armazenamento. 2001. 100f. Dissertação (Mestrado em Agronomia/Produção e Tecnologia de Sementes) Faculdade de Ciências Agrárias e Veterinárias, Universidade Estadual Paulista, 2001.

FESSEL, S.A.; PANOBIANCO, M.; SOUZA, C.R.; VIEIRA, R.D. Teste de condutividade elétrica em sementes de soja armazenadas sob diferentes temperaturas. Bragantia, v.69, n.1, p.207-214, 2010.

PANOBIANCO, M.; MARCOS FILHO, J. Evaluation of the physiological potential tomato seeds. Seed Technology, v.23, n.2, p.151-161, 2001.

PANOBIANCO, M.; VIEIRA, R.D. Electrical conductivity 
and deterioration of soybean seeds exposed to different storage conditions. Revista Brasileira de Sementes, v.29, n.2, p. $97-105,2007$.

PANOBIANCO, M.; VIEIRA, R.D.; PERECIN, D. Electrical conductivity as an indicator of pea seed aging of stored at different temperatures. Scientia Agricola, v.64, p.119-124, 2007.

PONTES, C.A.; CORTE, V.B.; LIMA, E.E.; BORGES, R.C.G.; SILVA, A.G. Influência da temperatura de armazenamento na qualidade das sementes de Caesalpinia peltophoroides Benth. (sibipiruna). Revista Árvore, v.30, n.1, p.43-48, 2006.

SIMON, E.W.; RAJA HARUN, R.M. Leakage during seed imbibition. Journal of Experimental Botany, v.23, n.77, p.1076-1085, 1972.
VIEIRA, R.D. Teste de condutividade elétrica. In: VIEIRA, R.D.; CARVALHO, N.M. (Ed.). Testes de vigor em sementes. Jaboticabal: FUNEP, 1994. p.103-32.

VIEIRA, R.D.; KRZYZANOWSKI, F.C. Teste de condutividade elétrica. In: KRZYZANOWSKI, F.C.; VIEIRA, R.D.; FRANÇA-NETO, J.B. (Ed.). Vigor de sementes: conceitos e testes. Londrina: Abrates, 1999. cap.4, p.1-26.

VIEIRA, R.D.; PENARIOL, A.L.; PERECIN, D.; PANOBIANCO, M. Condutividade elétrica e teor de água inicial das sementes de soja. Pesquisa Agropecuária Brasileira, v.37, n.9, p.1333-1338, 2002.

VIEIRA, R.D.; TEKRONY, D.M.; EGLI, D.B.; RUCKER, M. Electrical conductivity of soybean seeds after storage in several environments. Seed Science and Technology, v.29, p.599-608, 2001. 